\title{
PENGARUH WORKPLACE STRETCHING EXERCISE TERHADAP PENURUNAN KELUHAN MUSCULOSKELETAL DISORDERS(MSDS) PADA PEKERJA BATIK TULIS DI KECAMATAN SOKARAJA
}

\author{
EFFECT OF WORKPLACE STRETCHING EXERCISE TO REDUCE \\ MUSCULOSKELETAL DISORDERS (MSDS) COMPLAINT \\ IN BATIK WORKERS AT SOKARAJA DISTRICT
}

\author{
Siti Harwanti, Nur Ulfah, Budi Aji \\ Program Studi Kesehatan Masyarakat Fakultas Ilmu-Ilmu Kesehatan \\ Universitas Jenderal Soedirman
}

\begin{abstract}
Batik maked process especially "mbironi", is done in sit position. If this position maintained for a long period, that could be cause muscle strain which may lead into musculoskeletal disorders. The research was aim to know the effect of Workplace Stretching Exercise (WSE) to reduced MSDs in hand-made batik workers.The research was quasy experimental by non-equivalent control group design. Subjects were 37 female handmade batik workers used purposive sampling. Data analysis used Friedman test and Wilcoxon test, then for two independent sample used Independent $t$ Test and Mann Whitney test with significancy level at $5 \%$ or $\alpha=0,05$. Analysis result show that there is no difference in MSDs on experiment and control group after pre-test which had p-value $=0,371(>0,05)$. The result of middle-test and posttest $p$ value $=0,000(<0,05)$ that there is significant mean difference of MSDs between experiment and control group. Based on the middle-test and post-test analysis result, it could be conclude that there is an effect of WSE to reduce MSDs of handmade batik workers.
\end{abstract}

Keywords:MSDs, WSE, Handmade Batik Workers

\begin{abstract}
ABSTRAK
Proses pembuatan batik tulis, khususnya "mbironi", dikerjakan dalam posisi duduk. Apabila posisi duduk seperti ini dipertahankan dalam jangka panjang, akan menimbulkan ketegangan otot yang kemudian menimbulkan keluhan pada sistem muskuloskeletal. Tujuan dari penelitian ini adalah untuk mengetahui pengaruh dari Workplace Stretching Exercise (WSE)terhadap penurunan keluhan MSDs pada pekerja batik tulis. Penelitian ini termasuk desain quasi eksperimen dengan non-equivalent control group design. Jumlah sampel adalah 37 pekerja batik tulis berjenis kelamin wanita dengan teknik pemilihan sampel yaitu purposive sampling. Data diuji dengan uji Friedman dan uji Wilcoxon, serta uji Independent t Test dan uji Mann Whitney untuk sampel tidak berpasangan dengan tingkat kesalahan $5 \%$ atau $\alpha=0,05$. Diperoleh hasil uji statistik setelah pre-test $\mathrm{p}$-value $=0,317(>0,05)$ sehingga tidak ada perbedaan keluhan MSDs pada kelompok perlakuan dan kontrol. Kemudian setelah middle-test dan post-test diperoleh nilai $\mathrm{p}$-value $=0,000(<0,05)$, maka ada perbedaan rata-rata keluhan MSDs yang signifikan antara kelompok perlakuan dan kontrol. Dari hasil middle-test dan post-test dapat disimpulkan ada pengaruh WSE terhadap penurunan keluhan MSDs pada pekerja batik tulis kelompok perlakuan.
\end{abstract}

Kata Kunci: Keluhan MSDs, WSE, Pekerja Batik Tulis 


\section{PENDAHULUAN}

$\begin{array}{lcr}\text { Berbagai } & \text { industri banyak } \\ \text { menggunakan } & \text { mesin dalam } \\ \text { menyelesaikan } & \text { pekerjaannya pada } \\ \text { masa sekarang.Tetapi, masih banyak }\end{array}$ juga pekerjaan yang dikerjakan secara manual,meskipun akan memberikan tekanan fisik yang lebih berat pada pekerjanya. Salah satu akibat dari kerja secara manual adalah meningkatnya keluhan pada pekerja, seperti: sakit pada punggung, pinggang, sakit pergelangan, lengan tangan, kaki, ketegangan pada leher, kelelahan mata dan banyak keluhan lainnya (Tarwaka, 2014).Jumlah tenaga kerja di Indonesia menurut status pekerjaan utama, sebesar 47,5 juta orang $(40,19 \%)$ bekerja pada kegiatan formal dan 70,7 juta orang $(59,81 \%)$ bekerja pada kegiatan informal (Badan Pusat Statistik, 2014).

World

Health

Organization/WHO (2003), menyebutkan insidensi penyakit muskuloskeletal merupakan penyakit yang paling banyak terjadi dan diperkirakan mencapai 60,4\% dari semua penyakit akibat kerja. Menurut institusi yang bertanggungjawab untuk keamanan di tempat kerja yaitu Health and Safety Executive (HSE) pada tahun 2011-2012 di Eropa terdapat 439.000 kasus gangguan pada bagian otot rangka atau Musculoskeletal Disorders (MSDs) dari 1.037 .000 kasus cidera akibat pekerjaan terdapat 141.000 kasus MSDs baru yang ditemukan (Health and Safety Executive, 2012).

Industri batik di Banyumas masuk dalam sektor pekerjaan informal yang berkembang sangat cepat. Kecamatan Sokaraja masuk dalam sentra batik Banyumas sebagai salah satu kecamatan pemasok batik. Mayoritas pekerjaan yang dilakukan warga Kecamatan Sokaraja adalah membatik, dengan metode tulis dan dilakukan secara tradisional. Penelitian Harwanti dkk (2014) pada pekerja home industri batik tulis di desa Kauman Kecamatan Sokaraja Kabupaten banyumas, dari 60 pekerja batik yang semuanya adalah perempuan sebagian besar pekerja yaitu 52 pekerja $(86,7 \%)$ mengalami low back pain $(L B P)$.

Survei pendahuluan dilakukan peneliti kepada 10 pekerja batik di Desa Kauman, Sokaraja. 
Rata-rata umur pekerja batik tersebut adalah 40-60 tahun dengan jam kerja 1-8 jam per hari dan masa kerja ratarata 1-5 tahun. Hasil survei pendahuluan yang dilakukan menunjukkanbahwa risiko keluhan MSDs menurut Tarwaka (2015), yang termasuk dalam kategori risiko rendah sebanyak 2 orang (20\%), risiko sedang sebanyak 2 orang (20\%) dan risiko tinggi sebanyak 6 orang $(60 \%)$.

Terdapat beberapa metode peregangan otot (stretching) yang dapat dilakukan pekerja sebagai langkah untuk mencegah dan mengurangi keluhan muskuloskeletal. Salah satu metode alternatifnya adalah dengan melakukan Workplace Stretching Exercise(WSE) yang didesain dengan prinsip gerakan stretching (Rovitri, 2015).Penelitian Wahyono \& Saloko (2014) terhadap 64 pekerja wanita bagian sewing diperoleh hasil nilai $\mathrm{p}$ sebesar 0,000 ( $\mathrm{p}$ value<0,05) yang berarti bahwa terdapat perbedaan keluhan muskuloskeletal setelah pemberian WSE.Oleh karena itu, peneliti tertarik untuk melakukan penelitian mengenai Pengaruh WSE Terhadap Penurunan
KeluhanMSDsPada Pekerja Batik Tulis Di Kecamatan Sokaraja.

\section{METODE PENELITIAN}

Penelitian ini merupakan penelitian kuantitatif menggunakan desain studi Quasi Eksperimen dengan Non-equivalent Control Group Design. Sampel dalam penelitian ini adalah sebanyak 17 pekerja batik tulis kelompok perlakuan dan 20 pekerja batik tulis kelompok kontrol. Teknik pengumpulan data yang digunakan adalah menggunakan kuesioner Nordic Body Map yang dilaksanakan sebelum diberikan perlakuan (pretest), setelah 5 hari diberikan perlakuan (middle-test) dan setelah 10 hari diberikan perlakuan (posttest). Analisis data yang digunakan adalah Uji Friedman dengan uji lanjut Wilcoxon dan uji Independent $t$ Test serta uji Mann Whitney. Data hasil penelitian ditabulasi dengan menggunakan SPSS 16. uji normalitas data dengan menggunakan uji Saphiro Wilk.Selanjutnya, karena data tidak berdistribusi normal digunakan uji Friedman yang jika terdapat perbedaan, diuji lanjut menggunakan uji Wilcoxon, dengan tingkat 
kemaknaan/kesalahan $\quad 5 \%$ $(0,05) \cdot$ Kemudian dilakukan uji untuk mengetahui perbedaan antara kelompok perlakuan dan kelompok kontrol menggunakan uji Independentt Test jika data berdistribusi normal dan apabila data tidak berdistribusi normal maka menggunakan uji Mann Whitney.

\section{HASIL DAN PEMBAHASAN}

Karakteristik pekerja batik tulis di Kecamatan Sokaraja, berdasarkan umur didominasi oleh yang berusia $46-55$ tahun $(40,5 \%)$, masa kerja didominasi oleh masa kerja antara 5-10 tahun $(56,8 \%)$ dan lama kerja didominasi oleh lama kerja yaitu 7 jam $(62,2 \%)$. Hasil univariat gambaran keluhan MSDs pekerja batik tulis sebelum diberikannya perlakuan berupaWSE, menunjukkan persentase keluhan agak sakit,paling banyak adalah siku kiri, siku kanan dan lengan kiri bawah masing-masing sebanyak 10 orang $(58,8 \%)$, bagian tubuh dengan persentase keluhan sakit,paling banyak adalah peregelangan tangan kanan dan telapak tangan kiri masing-masing sebanyak 14 orang $(82,4 \%)$ dan bagian tubuh dengan persentase keluhan sangat sakit, paling banyak adalah punggung dan pinggang masing-masing sebanyak 4 orang $(14,7 \%)$ dari 17 orang kelompok perlakuan.

Hasil univariat gambaran keluhan MSDs pekerja batik tulis setelah diberikannya perlakuan berupa WSE pada hari kelima menunjukkan persentase keluhan agak sakit,paling banyak adalahpaha kiri sebanyak 15 orang $(88,2 \%)$, bagian tubuh dengan persentase keluhan sakit,paling banyak adalah punggung, lengan atas bagian kanan, pinggang, pinggul dan pantat masing-masing sebanyak 3 orang $(17,6 \%)$, dan bagian tubuh dengan keluhan sangat sakit,dialami padabahu kiri dan bahu kanan masing-masing sebanyak 1 orang $(5,9 \%)$ dari 17 orang kelompok perlakuan. Hasil univariat gambaran keluhan MSDs pekerja batik tulis setelah diberikannya perlakuan berupa WSE pada hari kesepuluh menunjukkan persentase keluhan agak sakit,paling banyak adalahbetis kanan sebanyak 11 orang $(64,7 \%)$ dan bagian tubuh dengan keluhan sakit dialami pada leher bagian atas, leher bagian bawah dan bahu kiri 
masing-masing sebanyak 1 orang $(5,9 \%)$ dari 17 orang kelompok perlakuan.

1. Perbedaan Tingkat Keluhan MSDs Sebelum Melakukan WSE, SetelaHari Kelima Melakukan WSE dan Setelah Hari Kesepuluh Melakukan WSE Kelompok Perlakuan
Analisis bivariat dilakukan untuk menganalisis tingkat keluhan MSDs, dengan menggunanakan uji Friedman yang di uji lanjut menggunakan uji Wilcoxon antara sebelum, setelah melakukan WSE pada hari kelima dan hari kesepuluh kelompok perlakuan, dan didapatkan hasil pada tabel 1.1 sebagai berikut :

Tabel 1. Perbedaan Tingkat Keluhan MSDs SebelumMelakukan WSE, Setelah Hari Kelima Melakukan WSE dan Setelah Hari Kesepuluh Melakukan WSE Kelompok Perlakuan

\begin{tabular}{|c|c|c|c|c|c|}
\hline Jenis Keluhan & $\begin{array}{c}\text { Mean } \\
\text { Pre-test }\end{array}$ & $\begin{array}{c}\text { Mean } \\
\text { Middle-test }\end{array}$ & $\begin{array}{c}\text { Mean } \\
\text { Post-test }\end{array}$ & p-value & Simpulan \\
\hline 0. Leher bagian atas & 1,12 & 2,06 & 2,35 & 0,000 & Ada Perbedaan \\
\hline 1. Leher bagian bawah & 1,18 & 2,00 & 2,35 & 0,001 & Ada Perbedaan \\
\hline 2. Bahu kiri & 1,18 & 2,12 & 2,47 & 0,001 & Ada Perbedaan \\
\hline 3. Bahu kanan & 1,24 & 2,12 & 2,47 & 0,001 & Ada Perbedaan \\
\hline 4. Lengan atas bagian kiri & 1,41 & 2,29 & 2,76 & 0,001 & Ada Perbedaan \\
\hline 5. Punggung & 1,06 & 1,88 & 2,41 & 0,004 & Ada Perbedaan \\
\hline $\begin{array}{l}\text { 6. Lengan atas bagian } \\
\text { kanan }\end{array}$ & 1,29 & 2,18 & 2,82 & 0,001 & Ada Perbedaan \\
\hline 7. Pinggang & 0,76 & 1,94 & 2,59 & 0,001 & Ada Perbedaan \\
\hline 8. Pinggul & 0,88 & 1,88 & 2,53 & 0,000 & Ada Perbedaan \\
\hline 9. Pantat & 1,41 & 2,18 & 2,82 & 0,008 & Ada Perbedaan \\
\hline 10. Siku kiri & 1,82 & 2,53 & 2,88 & 0,005 & Ada Perbedaan \\
\hline 11. Siku kanan & 1,82 & 2,47 & 2,82 & 0,008 & Ada Perbedaan \\
\hline 12. Lengan kiri bawah & 1,53 & 2,18 & 2,82 & 0,005 & Ada Perbedaan \\
\hline 13. Lengan kanan bawah & 1,41 & 2,18 & 2,71 & 0,002 & Ada Perbedaan \\
\hline $\begin{array}{l}\text { 14. Pergelangan tangan } \\
\text { kiri }\end{array}$ & 1,12 & 2,00 & 2,41 & 0,001 & Ada Perbedaan \\
\hline $\begin{array}{l}\text { 15. Pergelangan tangan } \\
\text { kanan }\end{array}$ & 1,06 & 2,00 & 2,41 & 0,001 & Ada Perbedaan \\
\hline 16. Telapak tangan kiri & 1,06 & 1,94 & 2,41 & 0,001 & Ada Perbedaan \\
\hline 17. Telapak tangan kanan & 1,12 & 2,00 & 2,47 & 0,001 & Ada Perbedaan \\
\hline 18. Paha kiri & 1,24 & 2,00 & 2,65 & 0,002 & Ada Perbedaan \\
\hline 19. Paha kanan & 1,29 & 2,06 & 2,71 & 0,002 & Ada Perbedaan \\
\hline 20. Lutut kiri & 1,59 & 2,29 & 2,94 & 0,001 & Ada Perbedaan \\
\hline 21. Lutut kanan & 1,71 & 2,24 & 2,94 & 0,007 & Ada Perbedaan \\
\hline 22. Betis kiri & 1,65 & 2,12 & 2,41 & 0,033 & Ada Perbedaan \\
\hline 23. Betis kanan & 1,59 & 2,12 & 2,35 & 0,003 & Ada Perbedaan \\
\hline 24. Pergelangan kaki kiri & 1,53 & 2,65 & 2,71 & 0,001 & Ada Perbedaan \\
\hline $\begin{array}{l}\text { 25. Pergelangan kaki } \\
\text { kanan }\end{array}$ & 1,65 & 2,65 & 2,76 & 0,001 & Ada Perbedaan \\
\hline 26. Telapak kaki kiri & 1,71 & 2,47 & 2,59 & 0,002 & Ada Perbedaan \\
\hline 27. Telapak kaki kanan & 1,71 & 2,47 & 2,59 & 0,002 & Ada Perbedaan \\
\hline
\end{tabular}


Tabel 1.1 menunjukkan hasil bahwa berdasarkan $\mathrm{p}$ value, dapat disimpulkan terdapat perbedaan keluhan MSDs yang signifikan pada semua bagian tubuh antara sebelum melakukan WSE, setelah melakukan WSE pada hari kelima dansetelah melakukan WSE pada hari kesepuluh dengan keseluruhan nilai $\mathrm{p}$ value< 0,05 . Nilai mean yang dihasilkan dalam penelitian ini menunjukkan peningkatan dari masa pre-test ke middle-test sampai post-test, yang berarti bahwa keluhan yang dirasakan responden semakin menurun secara signifikan. Bagian yang paling mengalami kenaikan mean tertinggi adalah pada bagian pinggang, yakni dari mean 0,76 menjadi 2,59 .

2. Hasil Pre-testKeluhan MSDs pada PekerjaBatikTulis Antara Kelompok Perlakuan dan Kelompok Kontrol

Analisis bivariat dalam penelitian ini juga dilakukan untuk mengetahui perbedaan keluhan MSDs pada pekerja batik tulis antara kelompok perlakuan dan kelompok kontrol, dengan menggunakan uji Independent $t$ Test dan uji Mann Whitney.

Tabel 2. Hasil UjiIndependent $\mathrm{t}$ Test, Pre-testKeluhan MSDs pada PekerjaBatikTulis Antara Kelompok Perlakuan dan Kelompok Kontrol

\begin{tabular}{ccc}
\hline Keluhan MSDs & p value & Keterangan \\
\hline $\begin{array}{c}\text { Pre-testKelompok Perlakuan x Pre-testKelompok } \\
\text { Kontrol }\end{array}$ & 0,317 & Tidak Ada Perbedaan \\
\hline
\end{tabular}

Hasil uji Independent $\mathrm{t}$ Testkeluhan MSDs pada pekerjabatiktulis antara kelompok perlakuan dan kelompok kontrol diperoleh nilai pvalue pre-test 0,317 (p value $>0,05)$.Sehingga, dapat disimpulkan tidak ada perbedaan keluhan MSDs pada pekerjabatiktulis antara kelompok perlakuan dan kelompok kontrol saat pre-test.

3. Hasil Middle-testKeluhan MSDs pada PekerjaBatikTulis Antara Kelompok Perlakuan dan Kelompok Kontrol

Tabel 3. Hasil UjiIndependent $t$ Test, Middle-testKeluhan MSDs pada PekerjaBatikTulis Antara Kelompok Perlakuan dan Kelompok Kontrol

\begin{tabular}{ccc}
\hline Keluhan MSDs & p value & Keterangan \\
\hline $\begin{array}{c}\text { Middle-testKelompok Perlakuan x Middle- } \\
\text { testKelompok Kontrol }\end{array}$ & 0,000 & Ada Perbedaan \\
\hline
\end{tabular}


Hasil uji Independent $\mathrm{t}$ pekerjabatiktulis antara kelompok Testkeluhan MSDs pada perlakuan dan kelompok kontrol saat pekerjabatiktulis antara kelompok middle-test.

perlakuan dan kelompok kontrol

4. Hasil Post-testKeluhan MSDs diperoleh nilai pvalue middle-test pada PekerjaBatikTulis Antara 0,000 ( $\mathrm{p}$ value $<0,05$ ). Sehingga, dapat Kelompok Perlakuan dan Kelompok disimpulkan ada perbedaan yang Kontrol bermaknakeluhan MSDs pada

Tabel 4. Hasil UjiMann Whitney, Post-testKeluhan MSDs pada PekerjaBatikTulis Antara Kelompok Perlakuan dan Kelompok Kontrol

\begin{tabular}{ccc}
\hline Keluhan MSDs & p value & Keterangan \\
\hline $\begin{array}{c}\text { Post-testKelompok Perlakuan x Post-testKelompok } \\
\text { Kontrol }\end{array}$ & 0,000 & Ada Perbedaan \\
\hline
\end{tabular}

Hasil uji Mann Ardiansyah (2013) yang menyatakan
Whitneykeluhan MSDs pada bahwa pemberian neck pekerjabatiktulis antara kelompok exercisememberikan pengaruh perlakuan dan kelompok kontrol seperti stretching pada kekakuan otot diperoleh nilai pvalue post-test $0,000 \quad$ yang berkontraksi lama pada daerah (p value<0,05).Sehingga, dapat leher.

disimpulkan ada perbedaan yang Begitu pula di bagian bermaknakeluhan MSDs pada ekstremitas atas, menujukkan pekerjabatiktulis antara kelompok penurunan sampai pada angka 5,9\% perlakuan dan kelompok kontrol saat untuk keluhan sakit.Hasil penelitian post-test.

Setelah diberikan perlakuan berupa WSE keluhan MSDs bagian leher responden menurun sampai menunjukkan angka sebesar 5,9\% pada keluhan sakit. Hasil penelitian ini didukung oleh penelitian ini didukung oleh penelitian penelitian Yusnani (2012), yang menyatakan bahwa terdapat perbedaan keluhan muskuloskeletal pada petugas kesehatan gigi setelah diberikan latihan peregangan, dimana dalam melakukan pekerjaannya, 
bagian ekstremitas atas tubuh lebih sering digunakan. Baker (2012), menyebutkan bahwa dalam penelitianya yang membandingkan dua metode stretching memberikan pengaruh/efektivitas dalam menurunkan Carpal Tunnel Syndrome yang merupakan salah satu jenis MSDs pada bagian telapak dan pergelangan tangan.

Bagian punggung responden juga menunjukkan penurunan keluhan sampai pada angka $0 \%$ untuk keluhan sangat sakit dan keluhan sakit.Hasil penelitian ini didukung oleh penelitian Anggraeni (2015), yang menyatakan bahwa stretching bermanfaat untuk menurunkan nyeri punggung bawah/pinggang pada pekerja bagian knitting gantung dimana hampir $90 \%$ responden pelatihan mengalami penurunan tingkat nyeri setelah diberikannya stretchingselama kurun waktu yang telah ditentukan. Dari hasil yang diperoleh, bagian pinggang pada awalnya menunjukkan tingkat keluhan paling tinggi dibandingkan dengan tingkat keluhan di bagian lain. Yaitu, dilihat dari nilai mean yang dihasilkan saat pre-test sebesar 0,76 yang kemudian meningkat menjadi 1,94 saat middletest dan meningkat lagi sebesar 2,59 saat post-test, dengan $\mathrm{p}$ value $=$ 0,001 $\quad(\mathrm{p}<\quad$ 0,05). Semakin meningkat/naiknya nilai mean pinggang ini, menunjukkan bahwa keluhan yang dirasakan responden semakin menurun secara signifikan.

Begitu pula di bagian ekstremitas bawah, menujukkanpenurunan sampai pada angka $0 \%$ untuk keluhan sangat sakit dan keluhan sakit.Hasil penelitian ini didukung oleh penelitian Lestari (2014), yang menyatakan bahwa terdapat pengaruh stretchingyang diberikan kepada perawat terhadap keluhan muskuloskeletal dan di yakini sebesar $95 \%$ bahwa stretchingdapat menurunkan keluhan muskuloskeletal pada perawat terutama di bagian ekstremitas bawah.

WSE sebagai upaya intervensi yang dilakukan dengan tujuan menurunkan keluhan muskuloskeletal pada pekerja batik tulis dalam penelitian ini memiliki masa efektif 10 hari dengan waktu istirahat 2 hari setelah 5 hari latihan. Latihan dilakukan 1 kali setiap harinya di sela-sela waktu 
kerja.Gerakan stretching yang diaplikasikan pada pekerja batik ini adalah gerakan yang berfokus pada leher, bahu, lengan, tangan, punggung dan kaki yang berfungsi melenturkan otot-otot pada bagian yang difokuskan.

Penguluran atau peregangan pada otot-otot dilakukan dengan 29 gerakan secara bertahap, setiap gerakan dilakukan penahanan selama delapan detik untuk merasakan adanya tarikan pada otot-otot yang difokuskan. Latihan dilakukan di bawah pengawasan langsung peneliti selama 10 hari sejak dimulainya pretest dan program intervensi. Gerakan WSE ini dilakukan dengan 3 kali set/ulangan dan dengan waktu untuk sekali set rata-rata sekitar 6-7 menit.

Gerakan stretching ini sangat sederhana dan mudah dilakukan. Seperti yang diungkapkan oleh Bob Anderson (2010), bahwa peregangan dapat dilakukan hampir di segala tempat dan kapan saja,tidak memerlukan peralatan khusus, tidak memerlukan pakaian khusus dan tidak memerlukan ketrampilan khusus.Mekanisme penurunanderajat nyeriyang terjadipadaresponden penelitian iniadalahberhubungan dengan menurunnyaspasme ototdan peningkatansirkulasidarahpada otot. Hal ini sejalan denganteori gerbang kontrol(gatecontroltheory)yaitu melaluiefek stretchingdari WSE. Hasil penelitian ini didukung dengan penelitian Rovitri (2015) yang melakukan penelitian pada perawat di RSIA Badrul Aini Medan, menyatakan bahwa terdapat perbedaan keluhan MSDs setelah melakukanWSEdengan nilai $\mathrm{p}$ yang diperoleh sebesar 0,000 ( $\mathrm{p}$ value < $0,05)$.

Hasil uji Independent $\mathrm{t}$ test dan Man-Whitney keluhan MSDs pada pekerjabatiktulis antara kelompok perlakuan dan kelompok kontrol, diperoleh nilai pvalue pretest $(0,317>0,05)$ dan pada saatmiddle-test maupun post-test diperolehp value $(0,000 \leq 0,05)$. Sehingga, dapat disimpulkan ada perbedaan keluhan MSDs pada pekerjabatiktulis saat pre-test dan saatmiddle-test maupun post-test antara kelompokkontrol dan kelompok perlakuan.

Bekerja terlalu lama dengan posisi kerja yang statis dapat menyebabkan ketegangan pada 
otot.Apabila tidak diberikan suatu perlakuan apapun ketegangan pada otot ini akan menjadi nyeri pada bagian tertentu yang tidak dapat hilang. Hal inilah yang kemudian menyebabkan pada kelompok kontrol tidak terjadi perubahan keluhan MSDs yang berarti. Responden mengatakan bahwa selama ini tidak pernah melakukan aktivitas peregangan ataupun kegiatan lain yang dapat mengurangi keluhan MSDs yang mereka rasakan. Berbeda dengan kelompok perlakuan yang diberikan WSE sebagai intervensi peregangan dalam menurunkan keluhan MSDs. Menurut Bob Anderson (2010), dengan melakukanperegangan maka seseorang dapat mengurangi ketegangan otot, mencegah kram otot dan membangun kesadaran terhadap bagian tubuh tertentu terutama pada bagian tubuh yang sering digunakan untuk beraktivitas.

Penelitian Okananto (2014), mendukung hasil penelitian ini yang menyatakan bahwa, tidak ada perbedaan tingkat keluhan otot skeletal saat pre-test antara kelompok perlakuan dan kelompok kontrol pada pekerja bagian menjahit di
Susukan Semarang.Hasil ini juga didukung oleh penelitian Fatsiwi (2015), yang menyebutkan bahwa terdapat perbedaan antara kelompok kontrol dan kelompok perlakuan setelah diberikannya intervensi berupa senam ergonomis untuk mengurangi keluhan nyeri MSDs pada kelompok perlakuan.Dalam penelitian Fatsiwi juga menyebutkan, bahwa kelompok kontrol mengalami peningkatan nyeri MSDs yang dikarenakan tidak diberikan intervensi apapun.

\section{SIMPULAN DAN SARAN}

Ada pengaruh pemberian WSEterhadap penurunan keluhan MSDs, serta terjadi penurunan ratarata keluhan MSDs pada kelompok perlakuan setelah melakukanWSE pada hari kelima dan hari kesepuluh intervensi. Terdapat pula perbedaan keluhan MSDs antara kelompok perlakuan dan kelompokkontrol.Oleh karena itu, Pekerja batik tulis disarankan melakukan WSE setiap hari di sela-sela kegiatan membatik, untuk mengurangi keluhan MSDs yang dirasakan saat melakukan aktivitas kerja terutama di bagian pinggang. 


\section{DAFTAR PUSTAKA}

Anderson, B. 2002.Peregangan untuk Orang Kantoran. Diterjemahkan oleh Ratih Ramelan. PT Serambi Ilmu Semesta, Jakarta.

Anggraeni, Riawan R. 2015. Manfaat Peregangan Otot Terhadap KeluhanNyeri Punggung Bawah Pada Pekerja BagianKnitting Gantung PT Royal KorindahPurbalingga. Skripsi.Fakultas Ilmu KeolahragaanUniversitas Negeri Semarang, Semarang.

Ardiansyah, Iqbal. 2013. Pengaruh Pemberian Neck Exercise Dan Transcutaneus Electrical Nerve StimulationKonvesional TerhadapPenurunan Nyeri OtotLeher Pada Sopir Bus Malam.Skripsi. Fakultas Ilmu Kesehatan Universitas Muhammadiyah Surakarta, Surakarta.

Baker, Nancy A. 2012.The Comparative Effectiveness of Combined Lumbrical Muscle Splints and Stretches on Symptoms and Function in Carpal Tunnel Syndrome.Journal Physical Medicine and Rehabilitation,Volume 93 Nomor 1, hal : 110.

Fatsiwi, N.A. 2015. Pengaruh Peregangan Senam Ergonomisterhadap Skor Nyeri Musculoskeletal Disorders(MSDs) pada Pekerja Pembuat KalengAlumunium.Jurnal Keperawatan, Volume 1 Nomor 1.

Health and Safety Executive. 2012.Muskuloskeletal

Disorder.http://www.hse.gov.uk/Statistics/ca usdis/musculoskeletal/index.htm,diakses pada 7 April 2016.

Lestari, N. 2014.Pengaruh

Stretchingterhadap KeluhanMuskuloskeletal pada Perawatdi Ruang Ratna dan MedicalSurgical RSUP Sanglah. Skripsi.
Program Studi Ilmu Keperawatan Fakultas Kedokteran Universitas Udayana, Denpasar.

Oknanto, A. 2014.Pengaruh Pemberian Peregangan (Stretching) TerhadapPenurunan Keluhan Nyeri Pinggang Dan Nyeri PunggungBawah (Low Back Pain) Pada PekerjaBagian MenjahitCV Vanilla Production Susukan Semarang. Skripsi.Fakultas Ilmu KesehatanUniversitas Muhammadiyah Surakarta, Surakarta.

Rovitri, Anestia. 2015.Perbedaan Keluhan Muskuloskeletal Sebelum DanSesudah Pemberian Workplace StretchingExercisePada Perawat Di RSIA Badrul AiniMedan Tahun 2015.Jurnal terpadu Ilmu Kesehatan, Volume 5 Nomor 2.

Tarwaka. 2014.Keselamatan dan Kesehatan Kerja: Manajemen dan Implementasi K3 di Tempat Kerja. Harapan Press, Surakarta.

2015.Ergonomi Industri DasarDasar Pengetahuan Ergonomi dan Aplikasi di Tempat Kerja Edisi II Cetakan ke-2. Harapan Press, Surakarta.

Wahyono, Y., dan Saloko E. 2014. Pengaruh Workplace Exerciseterhadap KeluhanMuskuloskeletal pada Pekerjadi bagian Sewing CV. CahyoNugroho Jati (CNJ) Sukoharjo. Jurnal Terpadu Ilmu Kesehatan, Volume 3 Nomor 2.

World Health Organization. 2003.Preventing MusculoskeletalDisorders in The Workplace. Lang/Metze Atelier, Berlin.

Yusnani S. 2012 Pebedaan Keluhan Muskuloskeletal Sebelum Dan Sesudah Pemberian Perlakuan Latihan Peregangan Pada Petugas Kesehatan Gigi Di Puskesmas Kecamatan Medan Area Tahun 2012.Jurnal Kesehatan Lingkumgan dan Keselamatan Kerja, Volume 1 Nomor 1. 